\title{
Successful Management of a Complicated Ulcer Caused by Autoimmune Vasculitis, with Sildenafil Citrate in a Patient with Primary Antiphospholipid Syndrome and Transient Steroid-Induced Diabetes Mellitus: A Case Report and Literature Review
}

\author{
Fernando Grover-Páez*, Leonel García-Benavides, Ernesto Germán Cardona-Muñóz, \\ Carlos Gerardo Ramos-Becerra, Jesús Ricardo García-Corral, \\ Carlos Enrique Medina-García, Guillermo Adrián Alanis-Sánchez, \\ Sylvia Elena Totsuka-Sutto \\ Institute of Experimental and Clinical Therapeutics, Department of Physiology, University Center of Health \\ Sciences, University of Guadalajara, Guadalajara, Mexico \\ Email: ${ }^{*}$ ggroverp@hotmail.com
}

Received 29 April 2014; revised 25 May 2014; accepted 20 June 2014

Copyright (C) 2014 by authors and Scientific Research Publishing Inc.

This work is licensed under the Creative Commons Attribution International License (CC BY). http://creativecommons.org/licenses/by/4.0/

(c) (i) Open Access

\begin{abstract}
Antiphospholipid syndrome (APS) is a prothrombotic condition that can affect both the venous circulation and the arterial system. The deep veins of the lower extremities and cerebral blood flow are the most common sites of venous and arterial thrombosis, respectively. Skin ulceration and gangrene may be associated with an active vasculitis in patients with APS. These kinds of ulcers are considered intractable because healing is difficult to achieve. Using steroids as immunesuppressant therapy is still a basic part of managing APS and vasculitis. Nevertheless, in the presence of steroid-induced diabetes mellitus, the priority is to achieve faster wound healing, because of the potential complications that can develop due to metabolic dysfunction and augmented vulnerability to infection. Until recently, there were few reports demonstrating the benefits of the use of adjuvant phosphodiesterase- 5 inhibitors like sildenafil citrate in different clinical entities with courses like Raynaud's phenomenon, scleroderma, and resistance to vasodilator therapy. We present the first report demonstrating the additional benefit of sildenafil citrate for the integration of grafts in a patient with steroid-induced diabetes and APS who had ulcers due to vasculitis resistant to the usual vasodilator therapy.
\end{abstract}

${ }^{*}$ Corresponding author.

How to cite this paper: Grover-Páez, F., et al. (2014) Successful Management of a Complicated Ulcer Caused by Autoimmune Vasculitis, with Sildenafil Citrate in a Patient with Primary Antiphospholipid Syndrome and Transient Steroid-Induced Diabetes Mellitus: A Case Report and Literature Review. Journal of Diabetes Mellitus, 4, 189-193.

http://dx.doi.org/10.4236/jdm.2014.43027 


\section{Keywords}

\section{Autoimmune Vasculitis, Sildenafil Citrate, Steroid-Induced Diabetes Mellitus, Primary Antiphospholipid Syndrome}

\section{Introduction}

Antiphospholipid syndrome (APS) is a prothrombotic condition that can affect both the venous circulation and arterial system [1] [2]. The deep veins of the lower extremities and cerebral blood flow are the most common sites of venous and arterial thrombosis, respectively [2].

The presence of antiphospholipid antibodies (APAs) is recognized as one of the pathogenic mechanisms of action in APS, andis highly variable. When attached to membrane phospholipids, APAs can inhibit reactions in the coagulation cascade that are catalyzed by these membrane phospholipids, promoting proadhesive, proinflammatory, and prothrombotic effects on endothelial cells [3].

The major autoantigen for APAs is $\beta$-2-glycoprotein-1, which is a plasma apolipoprotein that mediates the binding of APAs to target plasma apolipoproteins on cells (e.g., platelets, monocytes, endothelial cells, and trophoblasts) [3]-[5]. Intensive research on the pathogenic mechanism during the past two decades led to various therapeutic strategies being proposed based on targeted therapies for APS [6]. However, the only validated treatment for APS is lifelong anticoagulation [7]. Antithrombotic drugs are currently used to prevent thromboembolic events in patients with APS [8], but there is undoubtedly a need to develop adjuvant therapies for this autoimmune disease when it is associated with the presence of vasculitis.

On the other hand, steroids continue to be used as an adjuvant therapy with most of these drug combinations, and are administered in pulses despite the known complications associated with their use. Steroid use is not limited to hematological disorders, but is also useful as an immunosuppressant in other disease conditions, especially autoimmune diseases. Adverse effects associated with the use of steroids include gastritis, glaucoma, hypertension, impaired glucose tolerance, and diabetes mellitus. The latter is a clinical condition that can occur as a result of impaired insulin secretion or action, or the destruction of pancreatic beta cells [9].

Therefore, we present the case of a patient with steroid-induced diabetes mellitus and APS complicated by vasculitis ulcers in which the adjuvant therapeutic effect of sildenafil citrate, an inhibitor of phosphodiesterase 5 (PDE-5), demonstrated additional benefits in the graft integration process.

\section{Case Report}

A 55-year-old male had a history of moderate smoking (10 cigarettes per day for 25 years), which was suspended because of his current condition. Starting in 1995 with the presence of severe pain in the popliteal space and enlargement of his left leg, an acute popliteal vein thrombus was identified by Doppler ultrasound. We investigated his risk factors for deep vein thrombosis (DVT) through laboratory tests, with the following results: negative anti-nuclear antibodies, anti-cardiolipin Ig Gantibodies (131.0 U.GPL/ml), anti-cardiolipin Ig Mantibodies (35.0 U·MPL/ml), anti- $\beta$-2-glycoprotein antibodies (IGG: $25 \mathrm{UG}$ ), and lupus anticoagulant positive. The tests were repeated 12 weeks later and the results were similar confirming the diagnosis of APS. Based on the lab results, antithrombotic treatment was initiated based on enoxaparin $60 \mathrm{mg} /$ day for seven days and acenocoumarol 4 mgs/day until a stable international normalized ratio of 3.5 was achieved. Neither steroids nor cyclophosphamide were indicated during this first episode.

After the first episode of DVT, the patient had four more relapses about a year or so apart, two on each leg, mainly because of lack of adherence to anticoagulant treatment. After the second relapse, the patient developed various sized ulcers in the distal segment of his legs. These resolved after rest, anticoagulant dose adjustment, and treatment with antibiotics because of a positive culture for coagulase positive Staphylococcus aureus.

In May 2012, five necrotic ulcers of different sizes reappeared in the distal segment of the patient's left leg. The largest was $102 \mathrm{~cm}^{2}$ (Figure 1(a)), which was biopsied, including its edges. The cutaneous histopathologycal study reported a non-inflammatory vascular thrombosis. Additionally, the patient complained of severe pain in both feet, and Raynaud's phenomenon (RP) in 5 toes; therefore, we added nifedipine (Adalat, Bayer Schering Pharma, Germany) at a dose of $10 \mathrm{mg}$ orally twice daily to relieve vasospasms, as well as rivaroxaban (Xarelto, 

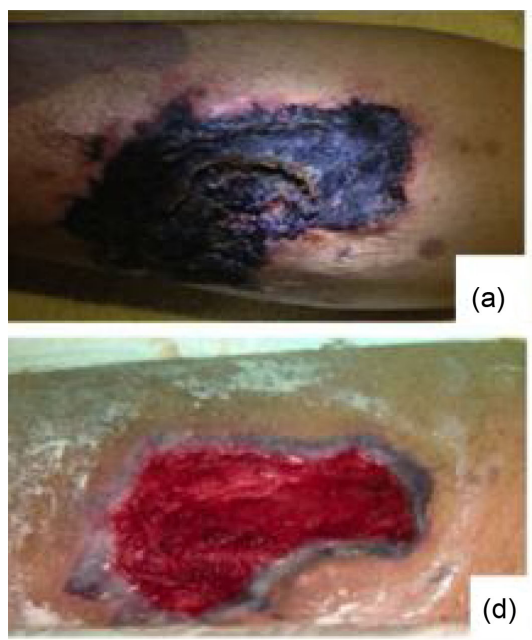

(d)

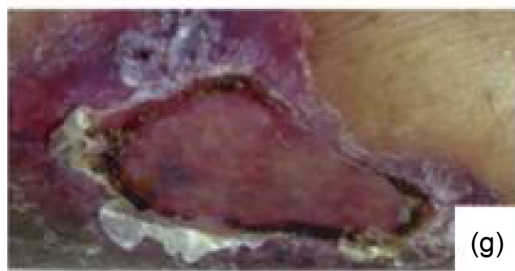

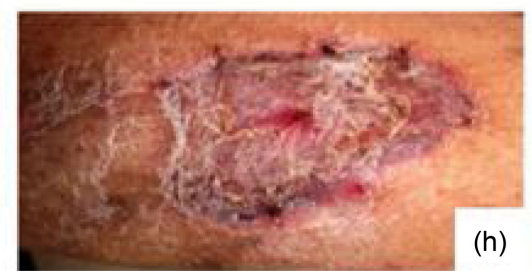
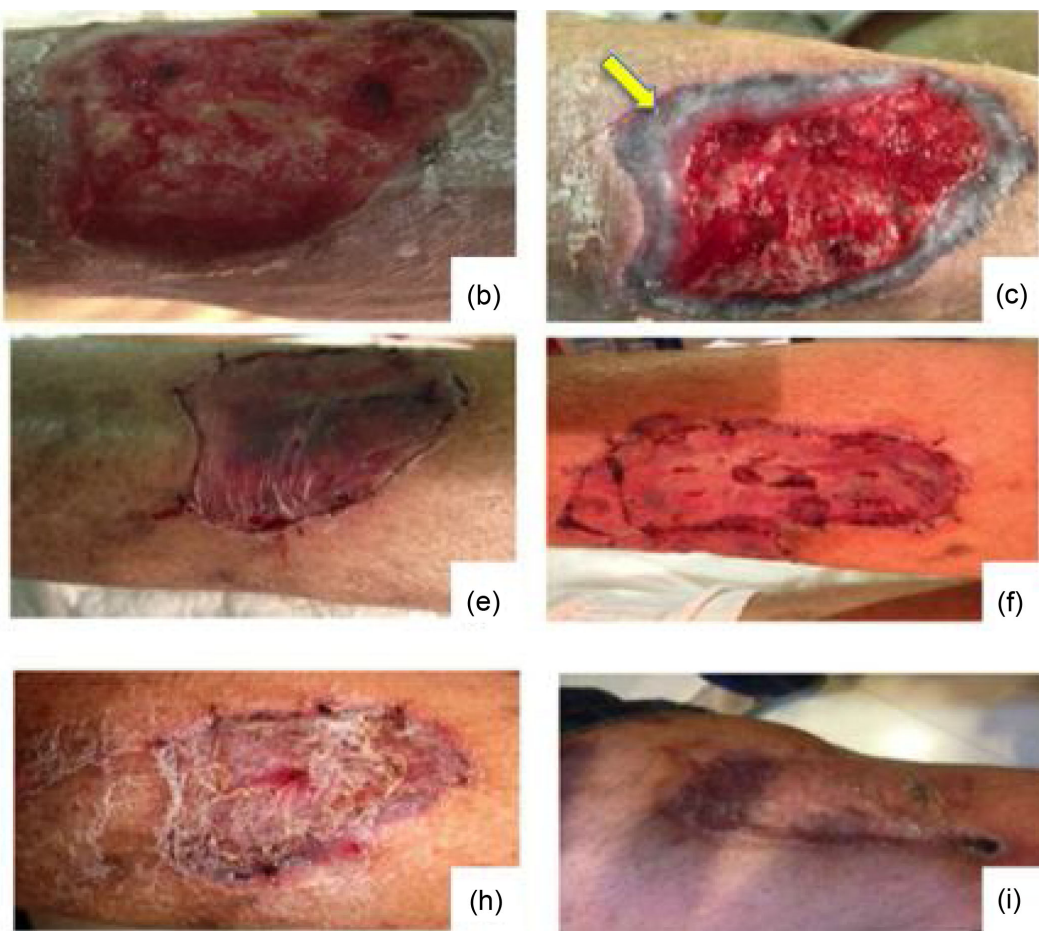

Figure 1. Iconographic evolution of lesions. (a) A necrotic ulcer appears with indurated edges; (b) Ulcersubsequent to surgical debridement; (c) Obvious vasculitis phenomenon (arrow); (d) Once treated with sildenafil citrate, the ulcer bed appears successfully integrated and the graft covers the ulcer defect (e f, g, h, i).

Bayer Schering Pharma, Germany) $10 \mathrm{mg} /$ day, and tramadol $200 \mathrm{mg}$ twice daily. However, there was no relief of symptoms after two weeks of treatment, so prednisone $(1 \mathrm{mg} / \mathrm{kg} /$ day), intravenous cyclophosphamide $1 \mathrm{~g} /$ day monthly, and oral gabapentin $600 \mathrm{mg}$ twice daily were prescribed. To treat positive anaerobic cultures, clindamycin 300 mg twice daily was administered, and fetid necrotic eschars that were covering the ulcers were debrided. Subcutaneous insulin glargine 12 units/day before a meal was given as a result of an unexpected rise in the patient's fasting serum glucose, which was over $200 \mathrm{mg} / \mathrm{dL}$.

\section{Case Evolution and Discussion}

Though rare, skin ulceration and gangrene can occur in patients with APS who have an active vasculitis. These kinds of ulcers are considered intractable because healing is difficult to achieve in patients who are exposed to immunosupressants, resulting in an uncertain prognosis [7].

Leg ulcers with a surface area larger than $100 \mathrm{~cm}^{2}$ are common in patients with autoimmune diseases and are the most difficult to heal. The primary treatment most be continued, although the administration of immunosuppressive therapies like steroids, cyclophosphamide, cyclosporin, and azathioprine slows the deposition of granulation tissue, inhibits the immune response, and promotes the infection [10].

The subsequent management of our patient consisted of wide surgical debridement and resection of the devitalized tissue (Figure 1(b)), infection control with intravenous ertapenem (Invanz, Merck Sharp \& Dohme) 1 g/day. For 2 weeks. Sildenafil citrate (Viagra, Pfizer, New York, NY) 50 mg/day was given because of a sudden violet coloring on the edge of the ulcer as shown in Figure 1(c) that we thought was RP secondary to vasculitis based on previous studies. The RP was reversed with PDE-5 inhibitors until graft integration (Figures 1(g)-(i)). The toes on both feet were discolored (images not shown).

When considering ischemic wounds, the literature indicates that the infection does not normally respond to systemic antibiotic therapy [11]. This patient also repeatedly applied peroxide solution to the wound. Nevertheless, hyperalgesia was an important limitation of this process. Pain due to wound healing causes patients to fear, distrust, and reject the process. For pain control, a tunneled peridural catheter was inserted to administer a combination of bupivacaine and morphine by infusion pump [12]. Prior to any wound manipulation, a lidocaine bolus 
was used. Multiple treatments have been proposed to accelerate the deposition of granulation tissue and decrease wound healing frequency [13]. Therefore, we employed fat dressings with sterile Vaseline and zinc oxide, which offers a moist environment and easier periodic replacement.

Adequate control of glucose was achieved through the insulin glargine, which improved good integration of the graft in order to obtain a complete cutaneous cover over all the lesions.

Recently, various possible sites of action of the therapeutic interventions used to treat lesions in patients with APS have been reported [14]. Not all of the interventions were successful, and others are not accessible to patients because of their costs or poor treatment adherence due adverse effects. We tried a new adjuvant therapeutic option that improves the vasospastic phenomenon, reduces pain symptoms associated with vasculitis, and favors ulcer cicatrization [15]. The doses of glargine and prednisone were also reduced.

Many animal experimental models in the literature have reported on the benefits of adjuvant use of PDE-5 inhibitors like sildenafil citrate [16]-[19] in different clinical entities similar to RP like scleroderma [15], including the use of tadalafil in patients with RP secondary to mixed connective tissue disease-scleroderma and resistance to vasodilator therapy [20]. The potential mechanism of action involves NO donation mediated by endothelial NO synthase [14].

\section{Conclusion}

This is the first report in the scientific literature demonstrating the additional benefit of the sildenafil citrate for the integration of grafts in a patient with APS and steroid-induced diabetes who had ulcers due to vasculitis that were resistant to usual vasodilator therapy.

\section{References}

[1] Brandt, J.T., Triplett, D.A., Alving, B. and Scharrer, I. (1995) Criteria for the Diagnosis of Lupus Anticoagulants: An Update. Thrombosis and Haemostasis, 74, 1185-1190.

[2] Miyakis, S., Lockshin, M.D., Atsumi, T., et al. (2006) International Consensus Statement on an Update of the Classification Criteria for Definite Antiphospholipid Syndrome (APS). Journal of Thrombosis and Haemostasis, 4, $295-306$. http://dx.doi.org/10.1111/j.1538-7836.2006.01753.x

[3] Cervera, R., Piette, J.C., Font, J., et al. (2002) Antiphospholipid Syndrome: Clinical and Immunologic Manifestations and Patterns of Disease Expression in a Cohort of 1000 patients. Arthritis Rheumatology, 46, 1019-1027. http://dx.doi.org/10.1002/art.10187

[4] Vega-Ostertag, M., Casper, K., Swerlick, R., Ferrara, D., Harris, E.N. and Pierangeli, S.S. (2005) Involvement of p38 MAPK in the Up-Regulation of Tissue Factor on Endothelial Cells by Antiphospholipid Antibodies. Arthritis Rheumatology, 52, 1545-1554. http://dx.doi.org/10.1002/art.21009

[5] Vega-Ostertag, M.E., Ferrara, D.E., Romay-Penabad, Z., Liu, X., Taylor, W.R., Colden-Stanfield, M., et al. (2007) Role of p38 Mitogen-Activated Protein Kinase in Antiphospholipid Antibody Mediated Thrombosis and Endothelial Cell Activation. Journal of Thrombosis and Haemostasis, 5, 1828-1834. http://dx.doi.org/10.1111/j.1538-7836.2007.02680.x

[6] Routy, B., Huynh, T., Fraser, R. and Séguin, C. (2013) Vascular Endothelial Cell Function in Catastrophic Antiphospholipid Syndrome: A Case Report and Review of the Literature. Case Reports in Hematology, 2013, Article ID: 710365.

[7] Lim, W. (2013) Antiphospholipid Syndrome. Hematology-American Society of Hematology Education Program, 2013, 675-680. http://dx.doi.org/10.1182/asheducation-2013.1.675

[8] Pudusseri, A., Shameem, R. and Spyropoulos, A.C. (2013) A New Paradigm Shift in Antithrombotic Therapy. Frontiers in Pharmacology, 4, 133. http://dx.doi.org/10.3389/fphar.2013.00133

[9] Kotila, T.R., Olutogun, T. and Ipadeola, A. (2013) Steroid Induced Diabetes Mellitus in Patients Receiving Prednisolone for Haematological Disorders. African Health Sciences, 13, 842-844

[10] Toyozawa, S., Yamamoto, Y., Kishioka, A., Yonei, N., Kanazawa, N., Matsumoto, Y., et al. (2009) Effective Treatment of Intractable Skin Ulcers Using Allogeneic Cultured Dermal Substitutes in Patients with Systemic Lupus Erythematosus. European Journal of Dermatology, 19, 594-596.

[11] Waqar, A.J., Habit, U.S., et al. (2009) Management of Diabetic Foot According to Wagner Classification and Frequency of Diabetic Foot Disease. Journal of Postgraduate Medical Institute, 23, 245-250.

[12] Schaffer, M.R., Tantry, U., van Wesep, R.A., et al. (1997) Nitric Oxide Metabolism in Wounds. Journal of Surgical Research, 71, 25. http://dx.doi.org/10.1006/jsre.1997.5137 
[13] Mejia Terrazas, G.E., Plancarte Sanchez, R., Reyes Chiquete, D. and Guajardo Rosas, J. (2009) Eficacia y seguridad de catéteres epidurales en pacientes oncológicos terminales ambulatorios. Reporte de casos. Revista Brasileira de Anestesiologia, 32, 186-190.

[14] Toyozawa, S., Yamamoto, Y., Kishioka, A., Nozomi, Y., Kanazawa, N. and Yatsumoto, Y., et al. (2009) Effective Treatment of Intractable Skin Ulcers Using Allogeneic Cultured Dermal Substitutes in Patients with Systemic Lupus Erythematosus. European Journal of Dermatology, 19, 594-596.

[15] Giannakopoulos, B. and Krilis, S.A. (2013) The Pathogenesis of the Antiphospholipid Syndrome. The New England Journal of Medicine, 368, 1033-1044. http://dx.doi.org/10.1056/NEJMra1112830

[16] Ng, W.K.Y., Rosenblatt, Y., Brock, G.B., O’Gorman, D.B. and Gan, B.S. (2010) Phosphodiesterase Inhibitors in Vascular Ischemia: A Case Report and Review of Their Use in Ischemic Conditions. Canadian Journal of Plastic Surgery, 18, e5-e9.

[17] Senthilkumar, A., Smith, R.D., Khitha, J., et al. (2007) Sildenafil Promotes Ischemia-Induced Angiogenesis through a PKG-Dependent Pathway. Arteriosclerosis, Thrombosis, and Vascular Biology, 27, 1947-1954. http://dx.doi.org/10.1161/ATVBAHA.107.147421

[18] Ulusoy, M.G., Uysal, A., Kocer, U., et al. (2005) Improved Flap Viability with Site-Specific Delivery of Sildenafil Citrate Using Fibrin Glue. Annals of Plastic Surgery, 55, 292-296. http://dx.doi.org/10.1097/01.sap.0000175483.35073.ea

[19] Sarifakioglu, N., Gokrem, S., Ates, L., Akbuga, U.B. and Aslan, G. (2004) The Influence of Sildenafil on Random Skin Flap Survival in Rats: An Experimental Study. British Journal of Plastic Surgery, 57, 769-772. http://dx.doi.org/10.1016/j.bjps.2004.04.014

[20] Tsai, J.W., Ayubi, F.S., Hart, K.L., et al. (2008) Evaluation of the Effect of Sildenafil and Vascular Endothelium Growth Factor Combination Treatment on Skin Flap Survival in Rats. Aesthetic Plastic Surgery, 32, 624-631. http://dx.doi.org/10.1007/s00266-008-9166-2 
Scientific Research Publishing (SCIRP) is one of the largest Open Access journal publishers. It is currently publishing more than 200 open access, online, peer-reviewed journals covering a wide range of academic disciplines. SCIRP serves the worldwide academic communities and contributes to the progress and application of science with its publication.

Other selected journals from SCIRP are listed as below. Submit your manuscript to us via either submit@scirp.org or Online Submission Portal.
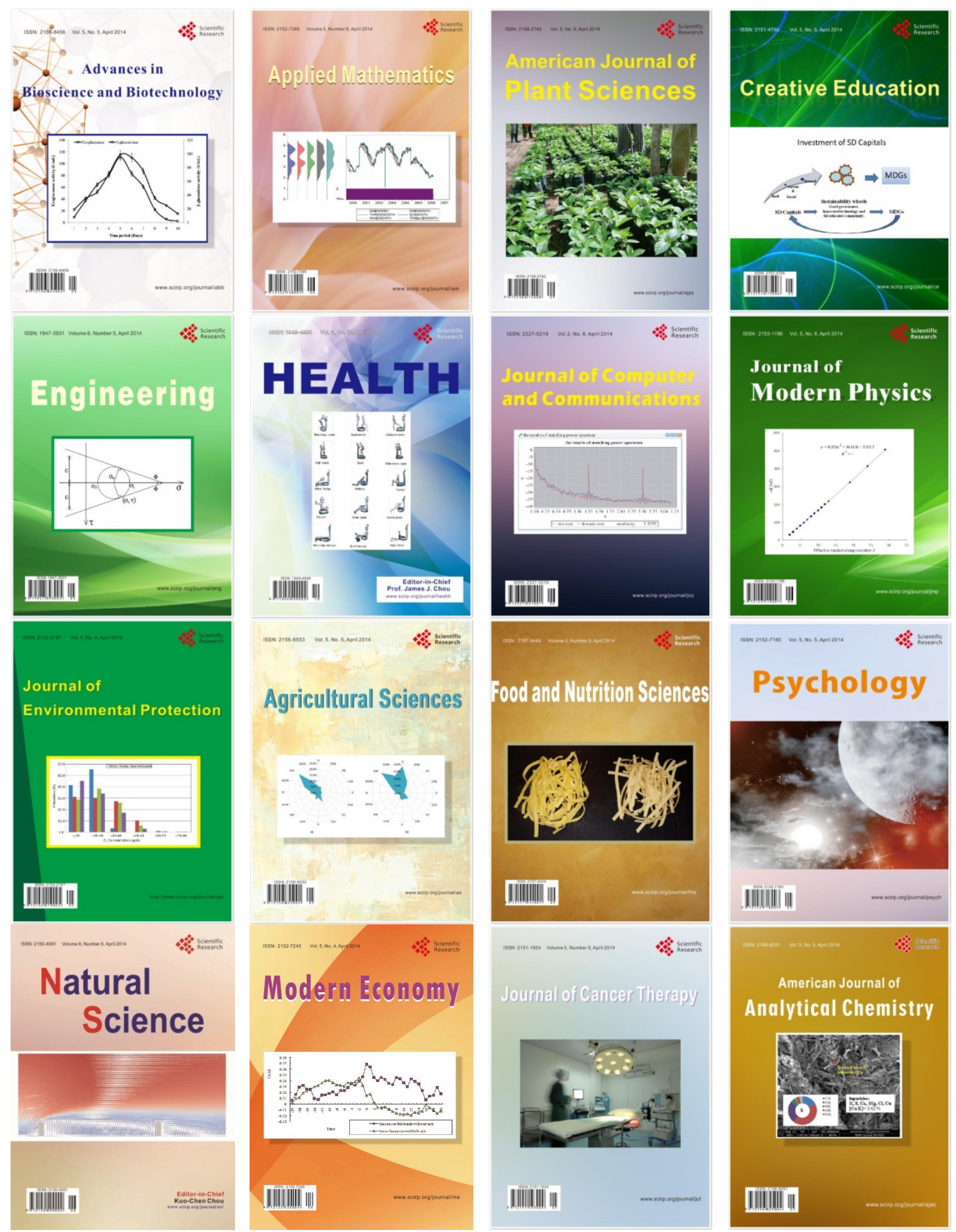